\title{
ENTREVISTA COM HÉCTOR VIGLIECCA ${ }^{1}$
}

Antônio Grillo²

O Professor Hector Vigliecca foi convidado pelo Curso de Arquitetura e Urbanismo da PUC Minas a proferir uma palestra na Semana Navegações do Curso, uma semana do semestre letivo dedicada exclusivamente a palestras, oficinas e viagens. Sua estadia foi breve, mas antes da palestra houve tempo para uma entrevista, conduzida pelo professor Antonio Grillo. Na conversa, foram abordados temas como a formação e a responsabilidade social do arquiteto, os problemas das cidades brasileiras, a relação do arquiteto urbanista com o cliente, a questão da inovação, e as transformações da sociedade contemporânea. Nas colocações do professor Hector Vigliecca, transparece uma postura convicta e aguerrida em prol da qualidade das cidades e da vida das pessoas que a habita, críticas a algumas práticas profissionais, e uma mescla de fascinação e melancolia perante o futuro.

\footnotetext{
1. Entrevista realizada em $18 / 04 / 2018$, durante a Semana Navegações do Curso de Arquitetura e Urbanismo da PUC Minas, quando o prof. Hector Vigliecca ministrou uma palestra, intitulada "Desvelando os paradigmas de um processo criativo".

2. Antonio Grillo é professor do Curso de Arquitetura e Urbanismo, e membro do Colegiado de Coordenação do Curso.
} 


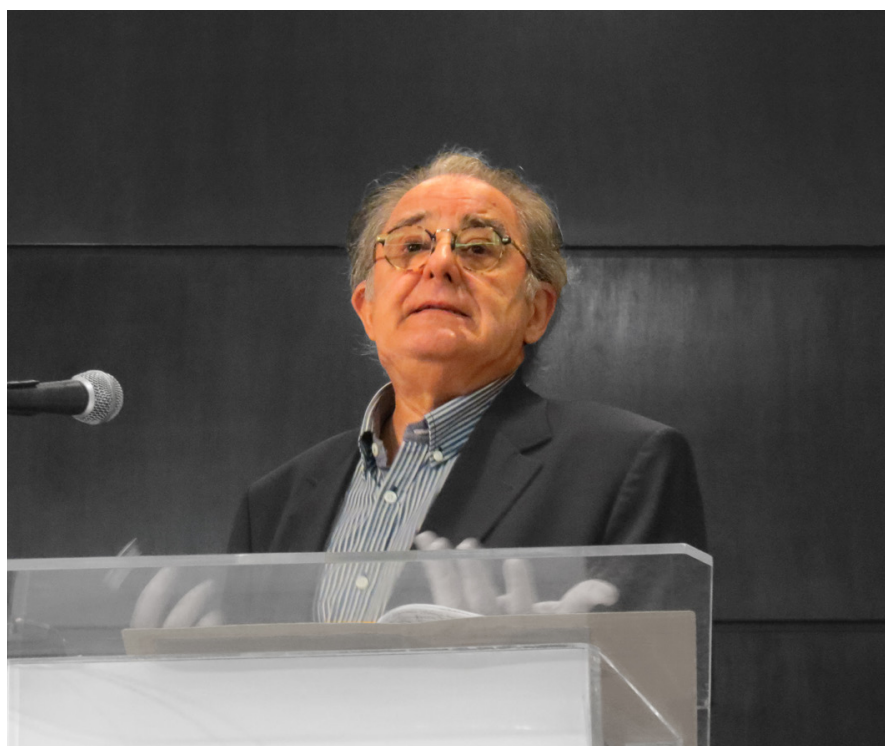




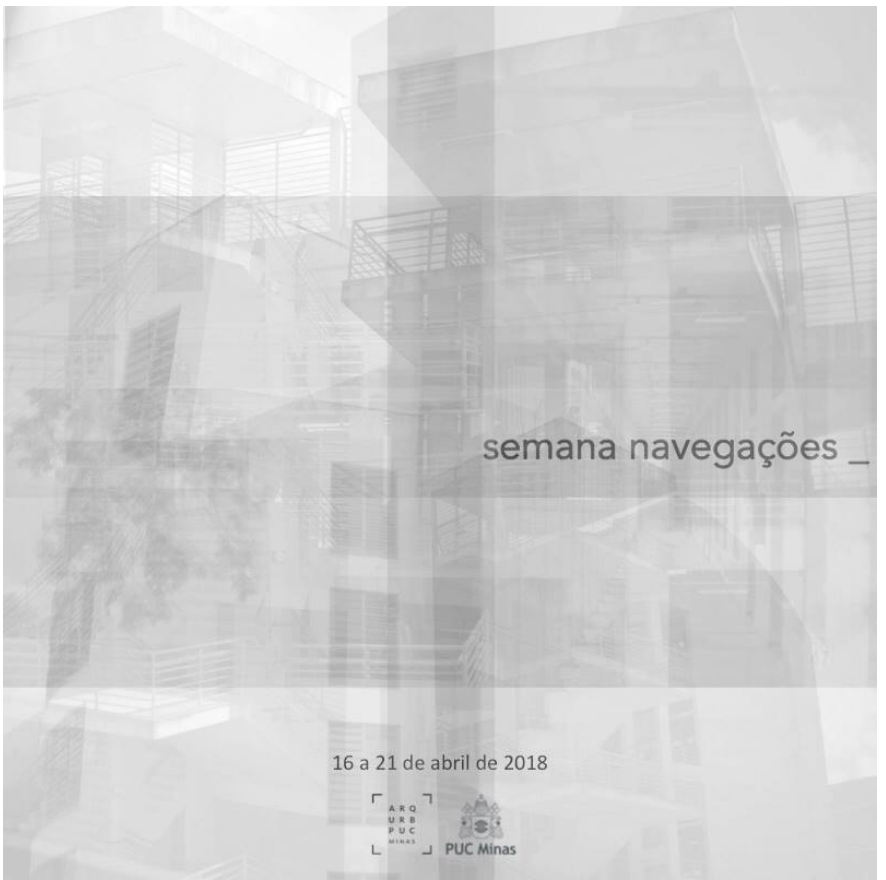

Figura 2 | Cartaz de divulgação da Semana de Navegações 2018. Fonte: PUC Minas, 2018. 


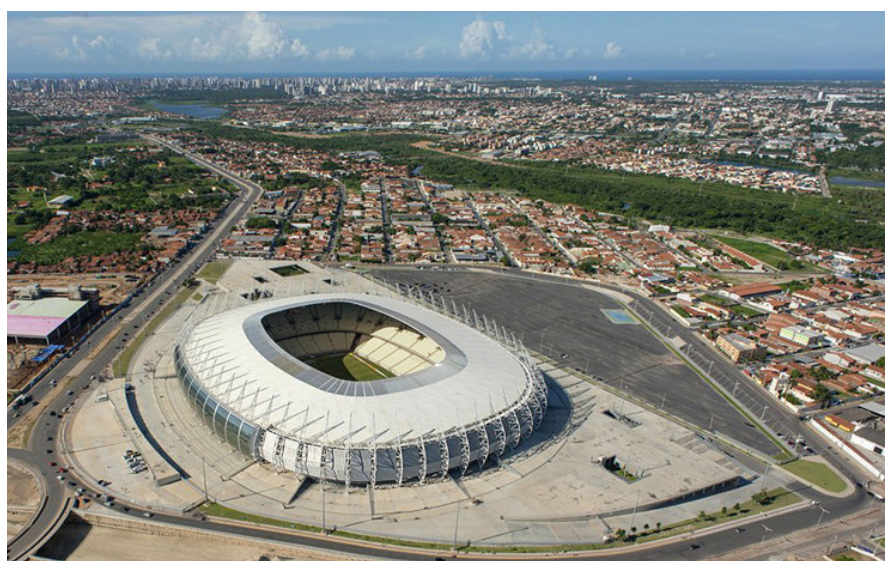

Figura 3 | Arena Castelão, projeto de reforma por Vigliecca e Associados, 2012. Fonte: Vigliecca e Associados (2012).

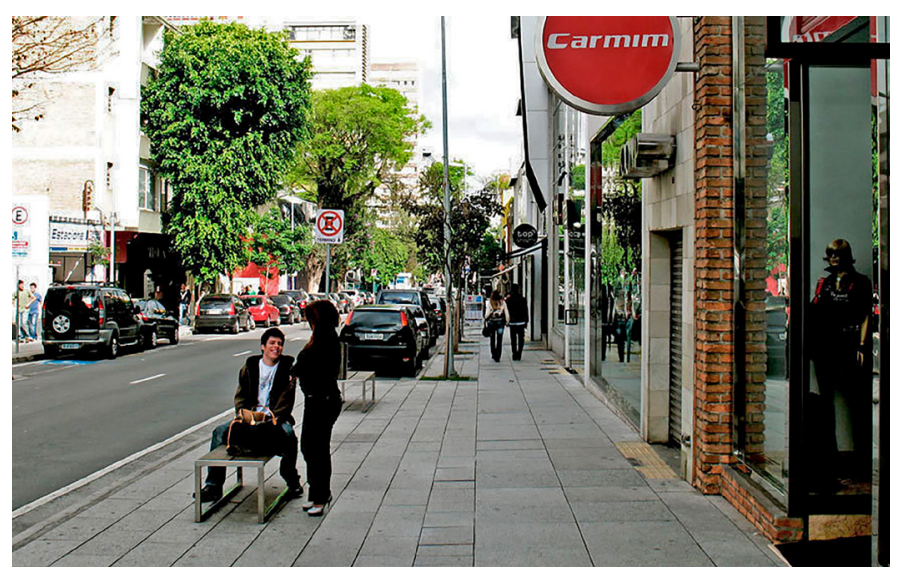

Figura 4 | Recuperação da rua Oscar Freire, 2002. Fonte: Vigliecca e Associados (2002). 


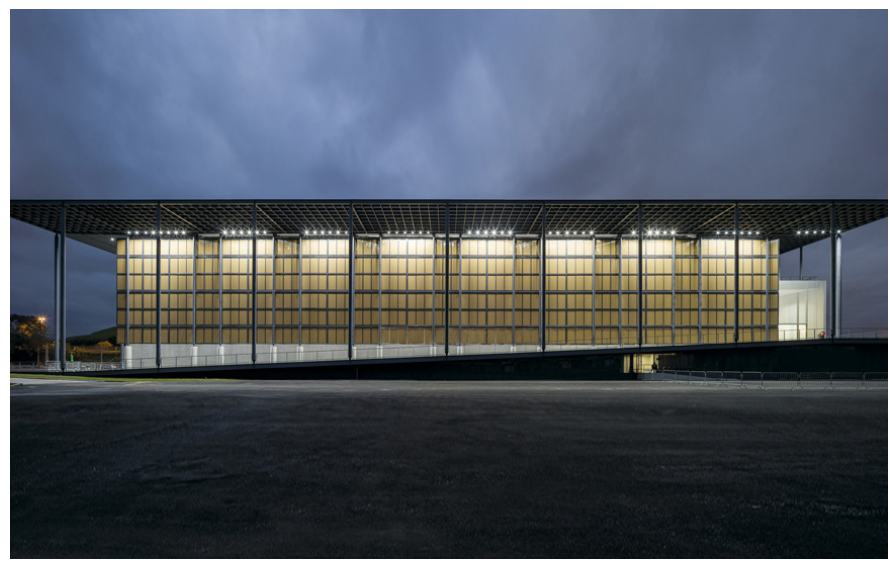

Figura 5 | Arena da Juventude, projeto de Vigliecca e Associados, 2013. Fonte: Vigliecca e Associados (2013).

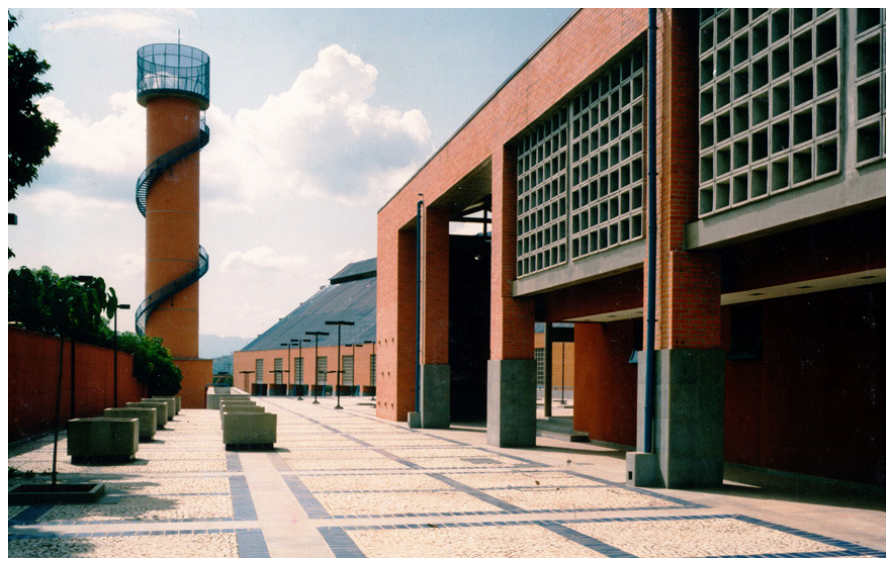

Figura 6 | SESC Nova Iguaçu, projeto de Vigliecca e Associados 1992. Fonte: Vigliecca e Associados (1992). 
Antonio Grillo: Gostaria de começar falando um pouco sobre sua trajetória profissional e a questão da formação do arquiteto. O senhor se formou no Uruguai, viveu na Europa por alguns anos, onde fez uma pós-graduação, trabalhou por muitos anos como diretor de arquitetura do $\mathrm{CNEC}^{3}$, o que imagino ter sido de grande importância para o senhor, e tem um trabalho longo e frutífero com escritório de arquitetura. No seu percurso profissional, desde a universidade, se faz presente uma marcada inquietação intelectual, social e política. Analisando suas obras, percebemos que elas sintetizam vários aspectos importantes da arquitetura: a associação da arquitetura com o urbanismo; a teoria e a prática; a arquitetura e a engenharia, ou o projeto e a técnica; e há também um investimento muito grande no que se refere à realidade social do país. Pensando na sua formação, com uma trajetória tão complexa e completa, o que o senhor acha que hoje é deficiente ou poderia ser otimizado, melhorado, na formação do arquiteto?

Héctor Vigliecca: Vivemos momentos complicados, não só no Brasil, mas no mundo inteiro. Penso que devemos refletir profundamente sobre qual é nossa função social, porque isso nunca ficou muito claro. Tenho experiência com clientes que não sabem exatamente qual é

3. CNEC - Consórcio Nacional de Engenheiros Construtores. Héctor Vigliecca foi chefe do Departamento de Arquitetura do CNEC de 1976 a 1985, durante o período áureo da engenharia do Brasil, quando projetou muitas obras de grande porte. 
a expertise do arquiteto. Um outro problema terrível no Brasil é o crescimento das cidades, e ainda parece que nós, arquitetos,, não estamos demostrando uma atitude clara sobre como devemos atuar fundamentalmente nas áreas críticas das cidades, como nas periferias e principalmente nas favelas, que hoje representam mais de 11 milhões de pessoas.

As cidades perdem a sua legibilidade, as pessoas ocupam todas as áreas e as cidades não param de se estender. As políticas do Estado insistem na atitude de fazer grandes conjuntos de habitação, conjuntos sempre construídos fora dos centros das cidades. Isso não quer dizer que nos centros não haja espaço; há espaço, mas a justificativa dada é que é mais barato fazer fora, mas isso é uma falácia, porque apesar do preço da terra ser menor, o custo de levar infraestrutura e equipamentos necessários ao atendimento da população torna tudo mais caro. $\mathrm{O}$ que acaba acontecendo de fato é um grande número de pessoas vivendo em situação de isolamento dos seus direitos como cidadãos; e já sabemos quais são as consequências desta política. Resumindo, o resultado é a degradação da própria cidade e, portanto, do ser humano. Então, a sua pergunta é sobre qual seria o ponto a que deveríamos dar atenção, certo? 


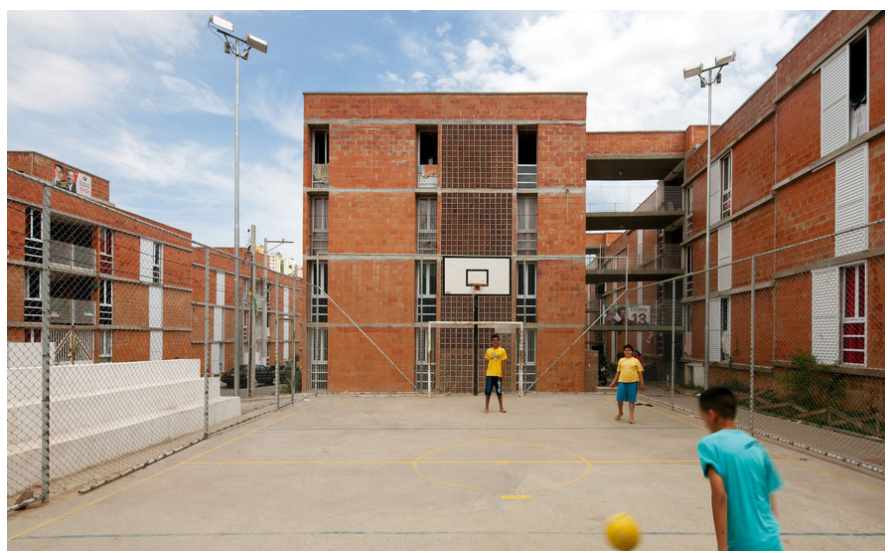

Figura 7 | Jardim Vincentina, 2010.

Fonte: Vigliecca e Associados (2010).

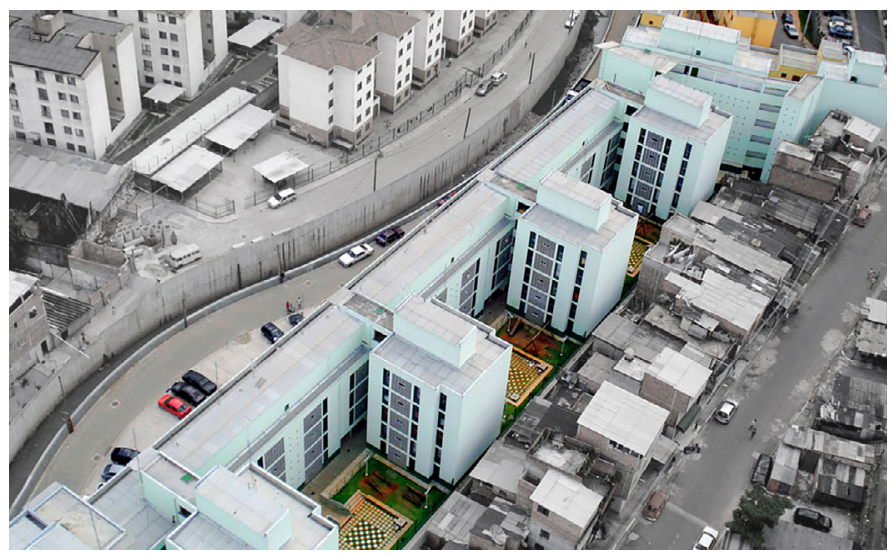

Figura 8 | Hlgienópolis Gleba A, 2004.

Fonte: Vigliecca e Associados (2004). 
AG: Sim, mais especificamente no que diz respeito à formação do arquiteto nas escolas.

HV: Devemos atentar à formação do arquiteto como um ser cultural completo. Temos que parar definitivamente de fazer objetos de design, e assumir a grande problemática das escolas no Brasil, que são o exercício da reflexão sobre a realidade. As escolas abrem suas portas para uma arquitetura de cópia. Precisamos ter ferramentas para raciocínios claros e eficientes sobre como construir nossa cidade. Hoje o trabalho de nosso escritório se concentra principalmente na reurbanização de favelas e nossa pergunta é sempre: “- Como fazer com que essas áreas críticas se transformem em cidade?". Não é uma tarefa fácil, mas estamos muito concentrados nesse tipo de ação, e consideramos hoje essa questão a única e grande ação obrigatória dos arquitetos. Não podemos conviver mais com essas periferias em que o homem ocupa, mas não a habita. Quem é então que vai tomar conta destas transformações? Nós, os arquitetos, temos esta como nossa tarefa fundamental, mas quem mais vai se ocupar disto? Quando os políticos tomam uma decisão sobre o assunto, é uma decisão de quantidade e de baixo custo, não é com isso que se faz uma cidade, não é com isso que se transformam pessoas em cidadãos. Esse é o nosso grande drama. As escolas estão mudando um pouco, mas, na época em 
que eu comecei a dar aulas, o assunto da cidade e o da periferia estavam fora dos currículos da escola. Atualmente, tais assuntos têm mais importância nas escolas. Ainda bem. Não sei se estou respondendo...

AG: Sim, está. É bom ouvir isso, pois este é um caminho que, de certa maneira, temos trilhado aqui; essa tem sido uma ênfase no curso da PUC Minas, creio estarmos em um bom caminho.

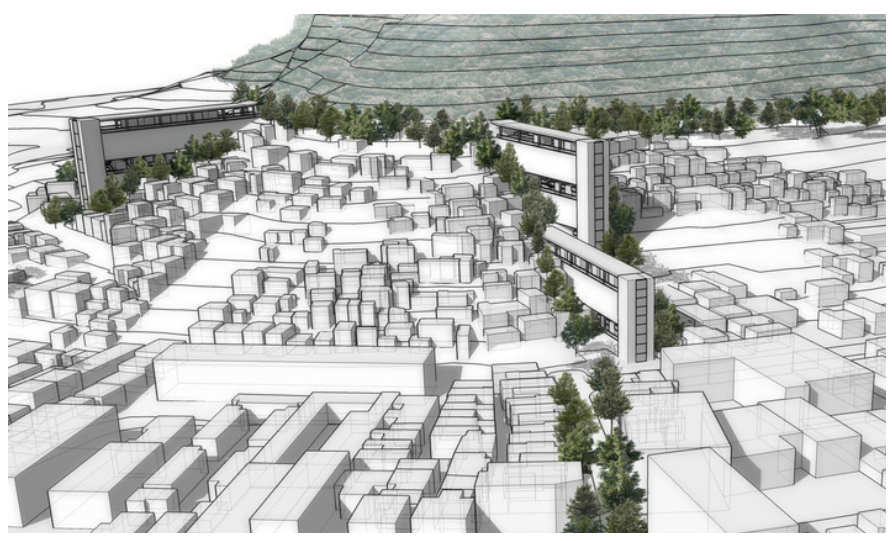

Figura 9 | Projeto para o Programa Morar Carioca, não construído.

Fonte: Vigliecca Associados (2011). 
O senhor escreveu sobre a ilusão da ordem, a consciência sobre a inconveniência ou a limitação de uma postura mais impositiva, moderna, capitalista e a incapacidade de compreender a população carente que tem que ser assistida, principalmente nas situações críticas, no contexto urbano. Gostaria de saber sua opinião sobre os processos participativos, ou seja, os mecanismos e estratégias de se ouvir a população para se intervir num determinado projeto, e as limitações disso na prática. Porque nem sempre temos condições de fazer isso; muitas vezes, lidamos com determinados projetos que estão condicionados a um cronograma limitado, ou em um contexto em que este procedimento é dificilmente factível. À parte essas limitações, enfrentamos esse dilema de tentar compreender e ouvir a população em um determinado contexto de projeto e, em contrapartida, a necessidade de em dado momento ter efetivamente que intervir, que projetar, determinar alguma coisa. Como o senhor vê esse dilema e as possiblidades dessa escuta, dessa permeabilidade, para que a experiência e a informação do outro possam ocorrer no projeto?

HV: Existe uma tendência errada de acreditar que não se pode fazer um projeto sem a participação da comunidade, o que não é verdade. Quando vamos a um médico, temos que explicar quais são os nossos sintomas, mas é o médico que tem as técnicas necessárias para aplicar o tratamento. Penso que o assunto da participa- 
ção não pode tirar a nossa responsabilidade de ouvir, de ver, para depois então interpretar essa realidade, ou seja, as soluções que damos não são literais, tentamos sempre encontrar hipóteses através de uma interpretação do que estamos vendo, ouvindo e recebendo como documentação, mas nesta fase não trabalhamos com a participação. Por exemplo, o doente, às vezes, participa enquanto explica qual é o seu problema. As decisões são tomadas em outro plano. Uma professora amiga minha, muito nova, contou-me: "Hector, nós fizemos um projeto junto com a população, fizemos tudo junto com eles e depois o projeto ficou horrível". Eu disse: "Bom, o problema é esse". Você faz junto com a população, mas a população não tem as técnicas e o conhecimento para fazer um projeto. Quem tem o conhecimento e a responsabilidade é você, o arquiteto. Você tem que ouvir e ver, e finalmente tem que interpretar essa realidade. Centrarei minha palestra agora exatamente sobre esse assunto.

AG: Analisando os projetos do senhor, vendo o que já publicou, incluindo suas aulas, que conhecemos pelo seu site, percebemos uma austeridade, um rigor grande com relação aos custos e à qualidade ambiental e estética dos projetos. No site, vemos que vocês do escritório têm as obras como diferenciais. Com frequência, aparece a palavra eficiência - eficiência nisso, eficiência naquilo, etc.-, mas, 
também, o senhor escreveu um artigo em que questionava os concursos públicos e citava a questão da inovação, colocava esse dilema da (não) inovação na história dos concursos. Se, por um lado, percebe-se uma postura muito rigorosa com relação a essa premissa da eficiência, por outro, tal postura poderia, eventualmente, ser conflitante com a questão da inovação. Poderia? (Porque eu penso que não...) O que o senhor considera ou preza mais no que se refere à inovação na arquitetura?

HV: Essa palavra é sempre mal interpretada, inovação. Vamos colocar um exemplo banal de inovação: um arquiteto acha que se colocar a janela em posição diferente ou usar algum material inédito está inovando, ou coisas desse tipo; eu entendo que inovação não é isso. Eu sou um leitor de Lucrécio, que era um filósofo latino, e ele tem uma explicação muito bonita a respeito dos átomos se combinarem e recombinarem sem uma ordem preestabelecida, que ele chama declinatio, que poderia ser traduzido como virada. Epicuro, que era atomista, nos dizia que declinatio é quando apenas um pequeno movimento dos átomos desencadeia, coisas inesperadas. Nós entendemos que a inovação, portanto, pode ser apenas discretas recombinações de ideias para obter uma nova realidade.

AG: Isso tem muito a ver com a Ciência da Complexidade... 
HV: Não acredito na busca da inovação pela inovação. Aceitamos a realidade que temos e trabalhamos sutilmente sobre ela sem fazer grandes gestos que geralmente não passam de transformações apenas formais. Sempre entramos, portanto, na realidade abraçando as preexistências, nunca nos isolando dela. Não estamos desesperados pela inovação. A inovação reside na interpretação correta da realidade.

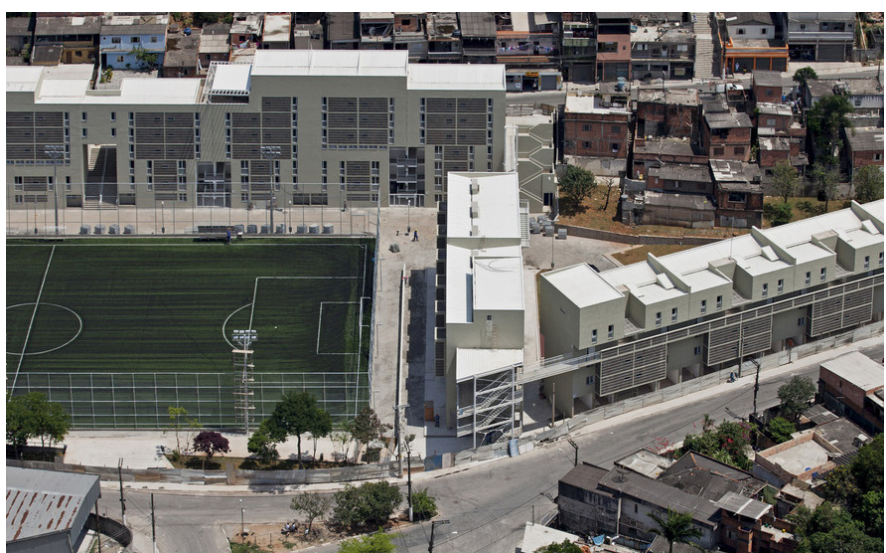

Figura 10 | Parque Novo Santo Amaro V, 2012.

Fonte: Vigliecca Associados (2012). 
AG: Uma última questão, para fechar, sobre a qual o senhor até começou a falar dela. Estamos em uma realidade urbana, social e política difícil, em que todos, de várias profissões, como nós, arquitetos, nos vemos em um grande desafio. A história profissional do senhor é uma história de resistência frente a esses desafios. O que o senhor teria a dizer hoje para estudantes de arquitetura e para jovens arquitetos, diante dessa nossa realidade, que é um pouco diferente de quando o senhor se formou?

HV: Em minha carreira, fui obstinado, martelando sempre no mesmo prego. Tremendamente obstinado, e isso não quer dizer que estejamos sempre repetindo uma mesma ideia, não é isso; tentamos, sim, refinar a nossa capacidade de ler a realidade, mas não transformamos essa procura em uma louca carreira de diferenciais formais. Não me interessam as arquiteturas com muito design, não mesmo; só me interessam as obras que tenham um diálogo com a realidade em que se insere. $O$ entorno pode ser ruim, pode ser bom, não interessa, é uma realidade que estamos enfrentando e transformando.

O futuro está complicado. Eu me sinto um pouco incapacitado para dar algum recado para os que estão se formando hoje, realmente. Talvez por conta desse tumulto que existe no mundo inteiro. Isso significa uma 
coisa: o mundo está se transformando, as pessoas estão se transformando. Você conhece o livro Sapiens ${ }^{4}$ ?

AG: Não.

HV: É um livro extraordinário! Conta a história da humanidade desde um viés inesperado, mas com final nada otimista quanto à transformação da nossa espécie e ao futuro da nossa existência. Se alguém me perguntar qual é o caminho a seguir, não sei o que responder. É muito difícil, porque vivemos em tempos de rápida transformação, em todos os aspectos: técnicos, sociais, pessoais e de gênero. Tudo parece estar se desfazendo para se transformar, sem dúvida, para tomar outra forma. Qual é essa outra forma? Ninguém pode dizer isso com muita certeza. Sabemos apenas o que acontece conosco hoje. Por isso, tento sempre estar em contato com gente jovem, que são os que estão construindo o futuro. Sinto muita energia ao dar aulas para jovens. Os jovens hoje têm muita vontade, são ativos. Cabe falar também das mulheres, que, de maneira rápida e surpreendente, invertem sua posição na sociedade, em todos os campos. Estou muito atento a isso.

AG: Acredito que o que se tem, assim, é uma história de um universo em transformação. Uma história bonita!

4. HARARI, Yuval Noah. Sapiens: uma breve história da humanidade, 2015. 
HV: Às vezes, sinto que este mundo já não é o meu. Fico todos os dias espantado com o que ouço, com o que vejo. Por um lado, é uma maravilha, por outro, sinto medo! Medo porque essas transformações estão mexendo com a permanência do mundo da maneira que o conhecemos.

\section{Referências}

SESC Nova Iguaçu. Vigliecca e Associados, 1992. Disponível em <http://www.vigliecca.com.br/pt-BR/projects/sesc-nova-iguacu>. Acesso em: 11. Nov. 2018.

RUA Oscar Freire. Vigliecca e Associados, 2002. Disponível em <http://www.vigliecca.com.br/pt-BR/projects/oscar-freire-street>. Acesso em: 11. Nov. 2018.

JARDIM Vicentina. Vigliecca e Associados, 2010. Disponível em $<$ http://www.vigliecca.com.br/pt-BR/projects/vicentina>. Acesso em: 11. Nov. 2018

ARENA Castelão. Vigliecca e Associados, 2012. Disponível em <http:// www.vigliecca.com.br/pt-BR/projects/castelao-arena >. Acesso em: 11. Nov. 2018.

PARQUE Novo Santo Amaro V. Vigliecca e Associados, 2012. Disponível em <http://www.vigliecca.com.br/pt-BR/projects/parque-novo-santo-amaro-v>. Acesso em: 11. Nov. 2018.

URBANIZAÇÃO de Heliópolis Gleba H. Vigliecca e Associados, 2013. Disponível em <http://www.vigliecca.com.br/pt-BR/projects/heliopolis-urbanization-glebe-h>. Acesso em: 11. Nov. 2018.

ARENA da Juventude. Vigliecca e Associados, 2013. Disponível em $<$ http://www.vigliecca.com.br/pt-BR/projects/youth-arena-3>. Acesso em: 11. Nov. 2018. 